\title{
AAV-mediated gene transfer for hemophilia
}

Katherine High, MD

\begin{abstract}
The goal of our work has been to establish an experimental basis for gene transfer as a method of treating hemophilia, an inherited bleeding disorder that results from the absence of functional factor VIII or factor IX. Using an adeno-associated viral vector derived from AAV serotype 2, we have shown in mice and in hemophilic dogs that we can achieve long-term expression ( $>3$ years) of clotting factor at levels that would result in an improvement of clinical symptoms of the disease. A phase I trial of intramuscular injection of AAV-F.IX showed no evidence of local or systemic toxicity in any of the subjects. Muscle biopsies showed evidence for gene transfer and expression by polymerase chain reaction, Southern blot, and immunohistochemistry. We have also shown that AAV-F.IX can be delivered into the portal veins of hemophilic dogs and that this results in high circulating levels of factor IX, on the order of $5 \%$ to $14 \%$, whereas delivery of similar doses to skeletal muscle results in factor levels of only $1 \%$ to $2 \%$. Based on these results, a trial of AAV-mediated liver-directed gene transfer for hemophilia B has been proposed and is reviewed here. Genet Med 2002:4(6, Supplement):56S-61S.
\end{abstract}

Key Words: gene transfer, adeno-associated virus, hemophilia $B$, factor IX

Using a variety of gene transfer strategies, investigators are pursuing a gene transfer approach for the treatment of hemophilia. This review addresses the current status of studies using one particular vector, recombinant adeno-associated virus (AAV), to deliver the factor IX gene to one of two different target tissues, either muscle or liver, as a strategy for treating hemophilia. Two themes will be apparent in this discussion: The first is the highly collaborative nature of work in clinical gene transfer, building as it does on developments in fields as diverse as genetics, immunology, biochemistry, virology, animal models of disease, and clinical trial design and conduct. The second related theme is the need for a very tight link between efforts in the basic laboratory and work going on in the clinical arena. As will become clear, it is critical in early phase gene transfer trials to extract as much information as possible from every subject who enrolls in a trial, and then to use that information to provide feedback for the continuing design and conduct of clinical investigation in gene transfer.

There are a number of general therapeutic strategies in which gene transfer can be used. The one that is most familiar is the replacement of a missing or defective gene in the setting of genetic disease. Gene transfer can also be used to augment the response to a conventional therapy, for example, to improve the response to L-dopa in Parkinson disease by supplying enzymes that promote conversion of L-dopa to dopamine, ${ }^{1,2}$ or

From the University of Pennsylvania School of Medicine, The Children's Hospital of Philadelphia, Philadelphia, Pennsylvania.

Katherine High, MD, University of Pennsylvania School of Medicine, The Children's Hospital of Philadelphia, 3615 Civic Center Blvd., 310 Abramson Research Center, Philadelphia, PA 19104

Received: September 4, 2002.

Accepted: September 30, 2002.

DOI: 10.1097/01.GIM.0000041455.30156.2C to enhance natural protective mechanisms, for example, by transferring genes encoding nitric oxide synthase into endothelial cells to prevent restenosis after stent placement for myocardial ischemia or infarction. ${ }^{3}$ The work discussed in this review is an example of the first type of strategy-the replacement of a defective gene.

\section{Rationale for gene transfer approach in hemophilia}

Hemophilia is a bleeding disorder caused by mutations either in the gene for factor VIII, termed hemophilia A, or the gene for factor IX, termed hemophilia B. Clinically the disease is characterized by frequent, spontaneous bleeding episodes, mostly into the joints and soft tissues. Recurrent bleeds into the joints, primarily the knees, ankles, and elbows, constitute the major morbidity of the disease, and eventually result in an arthropathy that limits range of motion in the joints. Bleeding can also occur into other critical closed spaces, such as the intracranial space, where it can be rapidly fatal. The disease is $\mathrm{X}$-linked, so that men are affected and women are carriers. The prevalence of the disease is evenly distributed worldwide. ${ }^{4,5}$

Currently, hemophilia is treated by the infusion of either recombinant or plasma-derived clotting factor concentrates, mostly in response to bleeding episodes. The widespread introduction of this form of therapy in the 1970s resulted in a dramatic improvement in life expectancy for people with hemophilia. Nevertheless, there are a number of disadvantages of this form of treatment that have fueled an interest in developing a gene-based approach to treating hemophilia. First and foremost, clotting factors have a relatively short half-life in the circulation; the inherent difficulty of treating a lifelong disease with frequent intravenous infusions of a medication is fairly clear. Initial clotting factor concentrates were manufactured from large pools of human plasma; these unfortunately proved 
highly efficient at transmitting viral blood-borne diseases, including hepatitis $\mathrm{B}$, hepatitis $\mathrm{C}$, and human immunodeficiency virus (HIV). ${ }^{6-11}$ The majority of patients with severe hemophilia treated before 1985 (when effective viral inactivation techniques were introduced) were infected with hepatitis and/or HIV. Third, because most people are treated in response to bleeds, rather than prophylactically, there is ongoing tissue damage that occurs to the joints in the interval between the time a bleed starts and the time a patient can infuse himself. In addition, clotting factors are very expensive. People with severe hemophilia may spend $\$ 50,000-\$ 100,000$ a year for concentrate alone, exclusive of their other medical expenses. It is estimated that more than half of the world's hemophilia population has no access to this treatment, and most of these individuals die during childhood and early adulthood from the disease. Finally, intravenous infusion is an inconvenient way to treat any disease, especially one that is lifelong. A successful gene transfer approach would allow people with hemophilia to continuously maintain some level of clotting factor in the circulation, so that bleeds could be prevented rather than treated after they have occurred. It would avoid all the risks of bloodborne disease transmission, would certainly be more convenient for patients, and would, one hopes, be less expensive and thus available to a larger percentage of the world's hemophilia population.

Among inherited diseases, hemophilia has a number of features that make it an excellent model for addressing problems related to gene transfer. First, although clotting factors are normally made in the hepatocyte, it turns out that biologically active coagulation factors can be synthesized in a variety of tissues. ${ }^{12,13}$ So tissue-specific expression is not required and that affords latitude in the choice of target tissue. Second, tight regulation of expression of the transgene is not required in the setting of hemophilia. People with severe disease have less than $1 \%$ circulating levels, but circulating levels of $1 \%$ to $5 \%$ are associated with a more moderate phenotype. So, if one can raise the levels by only a few percent, an improvement of the symptoms of the disease will result. Even if levels are raised to $100 \%$, they are still within normal limits, presenting a very wide therapeutic window. There are genetically engineered mice and naturally occurring dog models of hemophilia. ${ }^{14-20}$ The murine and canine factor VIII and IX genes are cloned and available, ${ }^{21,22}$ and this has facilitated an evaluation of gene transfer strategies before entering the clinic. Finally, because the genes for factor VIII and factor IX were cloned respectively 15 and 20 years ago, there is extensive experience with recombinant protein therapy. Thus the field has been able to define quite clearly what end points are required for therapeutic efficacy. As stated before, if one raises the levels by even a few percent, a phenotypic improvement of the disease is the likely result, and determining those end points is very straightforward. Two generations of experience in the clinical laboratory provide evidence that clinical symptoms correlate well with levels of clotting factor, measured in the circulation in a standard blood test.
A variety of gene delivery vehicles are available. Over the last decade, a number of groups have worked with many of them to try to establish an experimental basis for gene transfer for hemophilia (Table 1). The early vectors all had substantial limitations for treatment of an inherited disease like hemophilia, where the two major goals are sustained expression of the transgene and expression at levels high enough to make a difference in the disease. More recently it has been shown that recombinant $\mathrm{AAV}$ vectors directing expression of factor IX can result in sustained expression of F.IX in a large animal model of hemophilia. ${ }^{23}$ This work was made possible by investigation by a number of different laboratories that, in the mid-1990s, culminated with the initial reports of long-term expression of a transgene from a recombinant AAV vector. ${ }^{24,25} \mathrm{AAV}$ vectors are engineered in such a way that no viral coding sequences remain in the recombinant vector. Research at a number of laboratories has shown that they efficiently transduce certain nondividing target cells, including cells in the liver, ${ }^{26}$ the central nervous system, ${ }^{27}$ and skeletal muscle. ${ }^{24,25}$ We developed recombinant AAV vectors expressing blood coagulation factor IX. $^{21}$ The essential features of this are a strong viral promoter, the CMV promoter, driving expression of the human factor IX cDNA, which is interrupted by a portion of intron I of the factor IX gene (included because it increases levels of expression). In initial experiments this vector was introduced into skeletal muscle in mice. Following injection of vector into the hind limbs, the factor IX levels in the circulation rose gradually into the range of 250 to $350 \mathrm{ng} / \mathrm{mL}$, which corresponds to about $5 \%$ to $7 \%$ of normal levels in humans. ${ }^{21}$ If one could recapitulate that result in a human, it would raise their clotting factor, changing their phenotype from severe to mild-an exciting result. Factor IX expression lasted for a year, a long period in the life of a mouse, whereupon it began to deteriorate slowly. However, all mice still showed therapeutic levels of factor IX at the time of death from natural causes at the end of a normal life span. Injected muscle was biopsied and stained with an antibody to human factor IX. These studies showed a

\section{Table 1}

AAV for hemophilia B: muscle vs. liver
Muscle
Procedure safe, familiar, relatively noninvasive
Hepatitis B/C would not be a contraindication
Risk of germline transmission defined and low
Potentially reversible
Liver
Administration of vector requires invasive procedure
Effect of hepatitis on vector transduction and vice versa
Not reversible
Risks related to biodistribution (germline transmission)
Normal site of synthesis
Dose advantage 
mosaic-form pattern of staining, with positive fibers directly adjacent to negative fibers. The explanation for this observation eventually became clear in work carried out subsequently. ${ }^{28}$

\section{Studies in a large animal model of hemophilia}

We next sought to extend these results into a large animal model of hemophilia. The scale up from a mouse to a dog is about 400 - to 800 -fold, depending on the size of the dog. From a dog to a human is about 3 - to 10-fold, again depending on the size of the dog and the human. So if one can take the step from mouse to dog successfully, it greatly enhances the likelihood that one can make the subsequent step successfully as well. There were several questions that we hoped to answer in the dog model. One was the issue of scale-up of vector production, a formidable obstacle in the initial work with AAV. Second was the question of how efficiently factor IX synthesized in skeletal muscle would transit into the circulation in an organism larger than a mouse. Third, in terms of immune response to the transgene product, one may be misled if all the work is done on inbred strains of laboratory mice. The hemophilia dog model is an outbred strain, and in that regard is more like the very heterogeneous human population. Therefore, we concluded it was important to study immune response to the transgene product in an animal that does not normally make factor IX. So for these experiments, we collaborated with the group at the University of North Carolina at Chapel Hill who have maintained a hemophilia B dog colony for some 40 years. Earlier, our laboratory had cloned the canine factor IX $\mathrm{cDNA}^{18}$ and defined the mutation in these dogs, ${ }^{29}$ so reagents were available and the model was well characterized.

The AAV vector prepared for the canine experiments was similar to the first (vide supra), except that it drives expression of the canine factor IX gene. ${ }^{22}$ The hemophilia B dogs in Chapel Hill have a missense mutation and have normal levels of factor IX transcript. ${ }^{29}$ The protein structure is known in detail $^{30}$ and suggests that this missense mutation results in a substitution that almost certainly makes it impossible for the molecule to fold properly. So these animals have no circulating protein and have severe hemophilia-less than 1\% factor IX activity, and frequent spontaneous bleeding episodes, as is the case for humans with the disease.

The dogs ranged in size from about 6 to $20 \mathrm{~kg}$. Each was treated via intramuscular injection of vector at a number of sites on Day 1 of the protocol. The experiment was conducted in a dose escalation fashion, beginning with about $10^{11}$ vector genomes (vg) per kilogram, and gradually increasing to about $10^{13} \mathrm{vg} / \mathrm{kg}$. We then followed a series of coagulation parameters in the dogs. First we measured whole blood clotting time, a simple clotting test in which blood is drawn into a glass tube and the tube is tilted every 30 seconds. In a normal person (or a normal dog), the blood should clot in about 5 to 10 minutes, but in a hemophilic dog, even after 60 minutes the blood has not clotted. However, after injection of vector in these dogs, the whole blood clotting time shortens into the range of about
15 to 20 minutes, a range that has been maintained now for a period of more than 4 years in the first dogs. Much as we had seen in the mice, we observed long-term expression. The longer life spans of dogs allow us to continue to follow them, which will aid in developing data on duration of expression and on long-term safety. The circulating F.IX levels in dogs showed a clear dose response, so that the higher the dose of vector administered, the higher the circulating levels of factor IX, although the highest levels we achieved in the hemophilic dogs were on the order of $1.5 \%$, whereas in mice, levels of $5 \%$ to $7 \%$ were achieved. ${ }^{22}$ Nonetheless, because people with greater than $1 \%$ have a milder clinical course than individuals with less than $1 \%$, we felt that this was worth pursuing. We did not observe any evidence of toxicity related to the approach. One animal developed a transient inhibitory antibody to canine factor IX. On Western blot, starting about 2 weeks after vector injection, one could see an antibody to canine factor IX. It peaks at about 5 to 6 weeks after expression, and then it recedes. A clinical assay for the strength of an inhibitory antibody, the Bethesda titer, appears and exhibits a similar time course before disappearing. These transient inhibitory antibodies are a known side effect or complication of our current protein-based method of treating hemophilia, ${ }^{31}$ so while this is not a novel observation, it does emphasize that immune response to the transgene product remains a potential complication of the gene transfer approach as well as of the current protein-based approach. ${ }^{32,33} \mathrm{~A}$ number of toxicity studies were carried out in hemophilic dogs, and they demonstrated no toxicities associated with vector injection or transgene expression. Serial biopsies were performed at the site of vector injection, and there was never any evidence of muscle inflammation or deterioration as a result of the injections. Again, on muscle biopsy one sees a mosaic-form pattern when staining for canine factor IX at the site of the injection.

One other series of studies was carried out prior to extending this approach into the clinical arena. Clotting factors are highly posttranslationally modified glycoproteins. ${ }^{34}$ They are normally made in the liver, and it was critical to establish that the most important posttranslational modifications would take place accurately and efficiently when factor IX was made in skeletal muscle cells. There is a signal sequence that has to be cleaved off, as well as a propeptide sequence that is also removed. The $\mathrm{N}$-terminus of the protein contains a number of glutamic acid residues. In the mature protein, these have been modified to $\gamma$-carboxyglutamic acid (Gla); the enzyme responsible for this modification is $\gamma$-glutamylcarboxylase. It is abundant in the liver, but less abundant in skeletal muscle. ${ }^{35}$ There are also a number of glycosylation sites and a few other posttranslational modifications. We developed a cell culture system where we harvested myoblasts from human muscle biopsies, grew these in the laboratory, transduced them with our recombinant AAV vector, then collected the conditioned medium. ${ }^{12}$ We then worked out a purification scheme that would not bias for the collection of the properly posttranslationally modified material. We carried out biochemical analysis on this factor IX made in skeletal muscle cells. $\mathrm{N}$-terminal sequence 
analysis of the purified myotube-synthesized factor IX showed the correct sequence of the mature protein. Thus the signal sequence and the propeptide had been accurately and efficiently removed. In addition, based on chemical Gla analysis and on $\mathrm{N}$-terminal sequence analysis, $\gamma$-carboxylation of glutamic acid residues also appears to take place efficiently. In other experiments, the specific activity of factor IX made in myotubes was determined to be comparable with the specific activity of plasma-derived factor IX.

In other experiments in animal models, we had used the liver as the target for the vector. ${ }^{26,36}$ Thus we had to determine whether the initial attempt at clinical delivery of recombinant AAV would be into skeletal muscle or into the liver. Several factors influenced this decision. Intramuscular delivery of a vector involves a procedure that is safe and familiar, whereas administration of vector into the liver can be done, but it does require an invasive procedure in the interventional radiology suite. Most adults with severe hemophilia have been infected with hepatitis B and C..$^{37-39}$ We know this does not present a problem for vector delivery into the muscle, but it remains unclear what effect this may have for delivery into the liver. On the other hand, it must be admitted that there is a dose advantage in favor of going into the liver. Furthermore, as it is the normal site of synthesis, one can be very confident that all the posttranslational modifications will take place accurately and efficiently. Given the very limited experience with AAV vectors in humans when this work was begun, we decided to start with muscle as the target (Table 1).

\section{Initial human trials}

The initial trial of muscle-directed gene transfer for hemophilia B was an open-label dose escalation study with two or three subjects in each of three dose cohorts. Subjects underwent intramuscular injection of vector into the thigh. Subsequent laboratory studies and periodic muscle biopsies were used to determine whether gene transfer and expression had occurred. The primary goal of this work was to determine whether intramuscular injection of AAV could be done safely. This was unclear at the outset because it was the first experience with parenteral administration of recombinant AAV vectors. Most of us are infected with wild type AAV as children; some of us have preexisting antibodies to AAV. We wanted to determine whether this had any effect on gene transfer and expression. Obviously, a goal of the study is to determine the level and duration of expression of the transgene in human muscle. As with all new therapies for hemophilia, it is important to look for the prevalence of clinically significant inhibitors. Finally, the risk of germline transmission of the vector appeared to be undetectable in preclinical studies, but it remains imperative to understand its likelihood in humans. ${ }^{40-42}$ The major safety issues were outlined in the consent form and were listed as the possibility of insertional mutagenesis, the risk of inhibitory antibody formation, and the risk of germline transmission ${ }^{43}$ (Table 2).

\section{Table 2}

Goals of Phase I safety study in patients with severe hemophilia B using AAV vectors to deliver the gene for human Factor IX to skeletal muscle

Safety

Effect of preexisting immunity to AAV on gene transfer and expression

Level and duration of expression in human muscle

Prevalence of clinically significant inhibitors

Potential for germline transmission of vector

After a series of baseline studies are done, the patient is admitted to the clinical research center and undergoes intramuscular injections under ultrasound guidance. Subjects remain in the hospital for 24 hours and are then seen frequently in the outpatient department in the weeks after vector injection for a series of laboratory studies. After this, studies are conducted once a month during the first year, and yearly thereafter. Periodic muscle biopsies at the injection sites allow direct examination for evidence of gene transfer and expression.

Results from the treatment of the first three subjects have been published. ${ }^{44}$ Polymerase chain reaction analysis of body fluids showed no evidence of vector dissemination into the semen, but this effect will likely be dose-dependent, so that continued monitoring during dose escalation will be important. There was no evidence among the initial subjects of formation of inhibitory antibodies to factor IX, an important safety result. Neutralizing anti-AAV antibody titers are also measured in all subjects, to determine whether these can block transduction. Early evidence ${ }^{44}$ suggests that they do not block gene transfer, presumably because the vector is introduced in large doses into an anatomically limited space. Since the time required for vector binding and entry is probably brief, internalization is likely not limited even if titers go up after injection. It will be important to determine whether the same holds true in liver-directed gene transfer.

To date, the subjects who have been analyzed have shown evidence for gene transfer and expression. ${ }^{44}$ The subjects have also been free of serious adverse events, and administration of AAV to skeletal muscle has generally appeared quite safe in this study. ${ }^{45} \mathrm{~A}$ full-length report of the results of this trial is currently in preparation.

For the liver-directed strategy, continued engineering of the minigene cassette has resulted in ever-increasing levels of factor IX expression in the hemophilia B dog model. ${ }^{23,26,46}$ The most successful construct uses the human $\alpha_{1}$ antitrypsin promoter, with the apolipoprotein E enhancer, ${ }^{47}$ to drive expression of the factor IX cDNA. In dogs, this has resulted in circulating F.IX levels of $\sim 5 \%$ to $10 \%$ following portal vein administration of a dose of $\sim 1 \times 10^{12} \mathrm{vg} / \mathrm{kg}$; for comparison, the highest levels ever achieved in the muscle-directed approach in dogs were $1 \%$ to $2 \%$. Note that this dose is actually lower than doses already used in the muscle trial. In animal studies, if one compares transduced sections of liver to transduced sections of muscle, transduction rates are similar. However, it is likely that secretion of factor IX into the circulation is 
far more efficient from the liver as opposed to skeletal muscle. The proposed liver trial is similar in design to the muscle trial, except that the vector will be infused into the hepatic artery in a procedure done in the interventional radiology suite.

For AAV-2-based vectors, the general characteristics of transduction of skeletal muscle appear similar in mice, dogs, and humans. Parenteral administration of up to $2 \times 10^{12} \mathrm{vg} /$ $\mathrm{kg}^{46}$ has been well tolerated without any evidence of systemic or local toxicity. On muscle biopsy, we see clear evidence for gene transfer and expression in all of the subjects tested. The results of an ongoing liver-directed trial will establish whether this gene transfer strategy can be successfully translated from hemophilic dogs to patients with the disease.

\section{Acknowledgments}

The studies reviewed here were supported by NIH grants P01 HL64190, R01 HL61921, and PEGT U01 HL66948, and by Avigen, Inc., a company in which the author holds equity. This work represents the efforts of many individuals. The preclinical experiments are a collaboration between our group at the Children's Hospital of Philadelphia, Linda Couto's group at Avigen, and Mark Kay's laboratory at Stanford University. The clinical investigators who have led the clinical trials include Dr. Catherine Manno and Dr. Bert Glader, and a number of other individuals as well. Also, we have had very capable collaborators who direct the dog colonies at Chapel Hill, Dr. Tim Nichols, and at Auburn University, Dr. Clint Lothrop.

\section{References}

1. Bankiewicz KS, Eberling JL, Kohutnicka M, Jagust W, Pivirotto P, Bringas J, Cunningham J, Budinger TF, Harvey-White J. Convection-enhanced delivery of AAV vector in Parkinsonian monkeys: in vivo detection of gene expression and restoration of dopaminergic function using pro-drug approach. Exp Neurol 2000;164:2-14.

2. Sanchez-Pernaute R, Harvey-White J, Cunningham J, Bankiewicz KS. Functional effect of adeno-associated virus mediated gene transfer of aromatic L-amino acid decarboxylase into the striatum of 6-OHDA-lesioned rats. Mol Ther 2001;4:324330.

3. Melo JG, Zhang L, Kong D, Rezvani M, Pachori A, Lehtonen J, Yet S-F, Perrella MA, Dzau VJ. Intramyocardial AAV delivery of heme oxygenase-1 gene completely protects ischemic myocardial injury, restores left ventricular function and prevents remodelling. Mol Ther 2002;5:S295.

4. Kazazian HH, Tuddenham EGD, Antonarakis SE. Hemophilia A: deficiency of coagulation factor VIII. In: Scriver CR, Beaudet AL, Sly WS, Valle D, editors. The metabolic and molecular basis of inherited disease, Vol III, 8th ed. New York: McGraw-Hill, 2001:4367-4392.

5. Pollak ES, High KA. Hemophilia B: factor IX deficiency. In: Scriver CR, Beaudet AL, Sly WS, Valle D, editors. The metabolic and molecular basis of inherited disease, Vol III, 8th ed. New York: McGraw-Hill, 2001:4393-4413.

6. Blanchette VS, Vorstman E, Shore A, Wang E, Petric M, Jett BW, Alter HJ. Hepatitis C infection in children with hemophilia A and B. Blood 1991;78:285-289.

7. Brettler DB, Alter HJ, Dienstag JL, Forsberg AD, Levine PH. Prevalence of hepatitis C virus antibody in a cohort of hemophilia patients. Blood 1990;76:254-256.

8. Gerety RJ, Eyster ME, Tabor E, Drucker JA, Lucsh CJ, Prager D, Rice SA, Bowman HS. Hepatitis B virus, hepatitis A virus and persistently elevated aminotransferases in hemophiliacs. J Med Virol 1980;6:111-118.

9. Makris M, Preston FE, Triger DR, Underwood JC, Choo QL, Kuo G, Houghton M. Hepatitis C antibody and chronic liver disease in haemophilia. Lancet 1990;335: 1117-1119.

10. Ragni MV, Winkelstein A, Kingsley L, Spero JA, Lewis JH. 1986 Update of HIV seroprevalence, seroconversion, AIDS incidence and immunologic correlates of HIV infection in patients with hemophilia A and B. Blood 1987;70:786-790.

11. Rumi GM, Colombo M, Gringeri A, Mannucci PM. High prevalence of antibody to hepatitis $\mathrm{C}$ virus in multitransfused hemophiliacs with normal transaminase levels. Ann Intern Med 1990;112:379-380.
12. Arruda VR, Hagstrom JN, Deitch J, Heiman-Patterson T, Camire RM, Chu K, Fields PA, Herzog RW, Couto LB, Larson PJ, High KA. Posttranslational modifications of recombinant myotube-synthesized human factor IX. Blood 2001;97:130-138.

13. Bond M, Jankowski M, Patel H, Karnik S, Strang A, Xu B, Rouse J, Koza S, Letwin B, Steckert J, Amphlett G, Scoble H. Biochemical characterization of recombinant factor IX. Semin Hematol 1998;35:11-17.

14. Kundu RK, Sangiorgi F, Wu LY, Kurachi K, Anderson WF, Maxson R, Gordon EM. Targeted inactivation of the coagulation factor IX gene causes hemophilia B in mice. Blood 1998;92:168-174.

15. Bi L, Lawler AM, Antonarakis SE, High KA, Gearhart JD, Kazazian HH. Targeted disruption of the mouse factor VIII gene: a model for hemophilia A. Nat Genet 1995; 10:119-121.

16. Lin HF, Maeda N, Smithies O, Straight DL, Stafford DW. A coagulation factor IX-deficient mouse model for human hemophilia B. Blood 1997;90:3962-3966.

17. Wang L, Zoppe M, Hackeng TM, Griffin JH, Lee KF, Verma IM. A factor IXdeficient mouse model for hemophilia B gene therapy. Proc Natl Acad Sci U S A 1997;94:11563-11566.

18. Evans JP, Watzke HH, Ware JL, Stafford DW, High KA. Molecular cloning of a cDNA encoding canine factor IX. Blood 1989;74:207-212.

19. Cameron C, Notley C, Hoyle S, McGlynn L, Hough C, Kamisue S, Giles A, Lillicrap D. The canine factor VIII cDNA and 5' flanking sequence. Thromb Haemost 1998; 79:317-322.

20. Mauser AE, Whitney KM, Lothrop CD Jr. A deletion mutation causes hemophilia B in Lhasa Apso dogs. Blood 1996;88:3451-3455.

21. Herzog RW, Hagstrom JN, Kung SH, Tai SJ, Wilson JM, Fisher KJ, High KA. Stable gene transfer and expression of human blood coagulation factor IX after intramuscular injection of recombinant adeno-associated virus. Proc Natl Acad Sci U S A 1997;94:5804-5809.

22. Herzog RW, Yang EY, Couto LB, Hagstrom JN, Elwell D, Fields PA, Burton M, Bellinger DA, Read MS, Brinkhous KM, Podsakoff GM, Nichols TC, Kurtzman GJ, High KA. Long-term correction of canine hemophilia B by gene transfer of blood coagulation factor IX mediated by adeno-associated viral vector. Nat Med 1999;5: $56-63$.

23. Mount JD, Herzog RW, Tillson DM, Goodman SA, Robinson N, McCleland ML, Bellinger D, Nichols TC, Arruda VR, Lothrop CD, High KA. Sustained phenotypic correction of hemophilia B dogs with a factor IX null mutation by liver-directed gene therapy. Blood 2002;99:2670-2676.

24. Xiao X, Li J, Samulski RJ. Efficient long-term gene transfer into muscle tissue of immunocompetent mice by adeno-associated virus vector. J Virol 1996;70:8098 8108 .

25. Kessler PD, Podsakoff GM, Chen X, McQuston SA, Colosi PC, Matelis LA, Kurtzman GJ, Byrne BJ. Gene delivery to skeletal muscle results in sustained expression and systemic delivery of a therapeutic protein. Proc Natl Acad Sci U S A 1996;93: 14082-14087.

26. Snyder RO, Miao CH, Patijn GA, Spratt SK, Danos O, Nagy D, Gown AM, Winther B, Meuse L, Cohen LK, Thompson AR, Kay MA. Persistent and therapeutic concentrations of human factor IX in mice after hepatic gene transfer of recombinant AAV vectors. Nat Genet 1997;16:270-276.

27. Kaplitt MG, Leone P, Samulski RJ, Xiao X, Pfaff DW, O’Malley KL, During MJ Long-term gene expression and phenotypic correction using adeno-associated virus vectors in the mammalian brain. Nat Genet 1994;8:148-154.

28. Pruchnic R, Cao B, Peterson ZQ, Xiao X, Li J, Samulski RJ, Epperly M, Huard J. The use of adeno-associated virus to circumvent the maturation-dependent viral transduction of muscle fibers. Hum Gene Ther 2000;11:521-536.

29. Evans JP, Brinkhous KM, Brayer GD, Reisner HM, High KA. Canine hemophilia B resulting from a point mutation with unusual consequences. Proc Natl Acad Sci U S A 1989;86:10095-10099.

30. Brandstetter H, Bauer M, Huber R, Lollar P, Bode W. X-ray structure of clotting factor IXa: active site and module structure related to Xase activity and hemophilia B. Proc Natl Acad Sci U S A 1995;92:

31. Hoyer LW. Why do so many haemophilia A patients develop an inhibitor? $\mathrm{Br} \mathrm{J}$ Haematol 1995;90:498-501.

32. Brown BD, Lillicrap D. Dangerous liaisons: the role of "danger" signals in the immune response to gene therapy. Blood 2002;100:1133-1140.

33. Kay MA, High KA. Gene therapy for the hemophilias. Proc Natl Acad Sci U S A 1999;96:9973-9975.

34. Kaufman RJ, Wasley LC, Furie BC, Furie B, Shoemaker CB. Expression, purification and characterization of recombinant $\gamma$-carboxylated factor IX synthesized in Chinese hamster ovary cells. J Biol Chem 1986;261:9622-9628.

35. Wu SM, Stafford DW, Frazier LD, High KA, Chu K, Sanchez-Vega B, Solera J. Genomic sequence and transcription start site for the human $\gamma$-glutamyl carboxylase. Blood 1997;89:4058-4062. 
36. Nakai H, Herzog R, Hagstrom JN, Kung J, Walter J, Tai S, Iwaki Y, Kurtzman G, Fisher K, Couto L, High KA. AAV-mediated gene transfer of human blood coagulation factor IX into mouse liver. Blood 1998;91:4600-4607.

37. Ahmed MM, Multimer DJ, Elias E, Linin J, Garrido M, Hubscher S, Jarvis L, Simmonds P, Wilde JT. A combined management protocol for patients with coagulation disorders infected with hepatitis C virus. Br J Haematol 1996;95:383-388.

38. Aledort LP, Levine PH, Hilgartner M, Blatt P, Spero JA, Goldberg JD, Bianchi L, Desmet V, Scheuer P, Popper H, Berk PD. A study of liver biopsies and liver disease among hemophiliacs. Blood 1985;66:367-372.

39. Hanley JP, Jarvis LM, Andrews J, Dennis R, Lee R, Simmonds P, Piris J, Hayes P Ludlam CA. Investigation of chronic hepatitis $\mathrm{C}$ infection in individuals with haemophilia: assessment of invasive and non-invasive methods. Br J Haematol 1996;94: $159-165$.

40. Arruda VR, Fields PA, Milner R, Wainwright L, DeMiguel MP, Donovan PJ, Herzog RW, Nichols TC, Biegel JA, Razavi M, Dake M, Huff D, Flake AW, Couto L, Kay MA, High KA. Lack of germline transmission of vector sequences following systemic administration of recombinant AAV-2 vector in males. Mol Ther 2001;4:586-592.

41. Gene therapy and the germline. Nat Med 1999;5:245.

42. Farber D. Gene therapy: safer and virus-free? Science 2001;294:1638-1642.
43. www4.od.nih.gov/oba/rac/minutes/6-98min.htm. National Institutes of Health Recombinant DNA Advisory Committee Minutes. Bethesda, MD, June 18-19, 1998.

44. Kay MA, Manno CS, Ragni MV, Larson PJ, Couto LB, McClelland A, Glader B, Chew AJ, Tai SJ, Herzog RW, Arruda V, Johnson F, Scallan C, Skarsgard E, Flake AW, High KA. Evidence for gene transfer and expression of factor IX in haemophilia B patients treated with an AAV vector. Nat Genet 2000;24:257-261.

45. Manno CS, Glader B, Ragni MV, Thompson A, Ferreira Costa F, Chew AJ, Herzog RW, Arruda VR, Couto LB, McClelland A, Johnson F, Flake A, Skarsgard E, Armstrong E, Kay M, High KA. A phase I trial of AAV-mediated muscle directed gene transfer for hemophilia B. Blood 2000;96:800a.

46. Wang L, Takabe K, Bidlingmaier SM, Ill CR, Verma IM. Sustained correction of bleeding disorder in hemophilia B mice by gene therapy. Proc Natl Acad Sci U S A 1999;96:3906-3910.

47. Okuyama T, Huber RM, Bowling W, R. P, Kennedy SC, Flye MW, Ponder KP. Liver-directed gene therapy: a retroviral vector with a complete LTR and the ApoE enhancer-alpha(1)-antitrypsin promoter dramatically increases expression of human alpha(1)-antitrypsin in vivo. Hum Gene Ther 1996;7:637-645. 